\title{
Key Factors for Successful Entrepreneurship in Thailand
}

\author{
Michael Ha1, Uthit Siriwan², Chotika Ramabut², Nutchuda Thitikalaya2, \\ Tassanee Thitikanlaya ${ }^{2}$, Chutikarn Kiatnarong2 \\ ${ }^{1}$ Department of Mathematical Sciences, Xi'an Jiaotong-Liverpool University, Suzhou, China \\ ${ }^{2}$ Faculty of Business, Charisma University, Turk and Caicos Islands, United Kingdom \\ Email: Michael.Ha@xjtlu.edu.cn, U.siriwan@charismauniversity.info, C.Ramabut@charismauniversity.info, \\ N.Thitikalaya@charismauniversity.info, C.Kiatnarong@charismauniversity.info
}

Received May 2014

\begin{abstract}
A causal relationship among key critical success factors of successful entrepreneurs in Thailand is proposed. A new business innovation management model is established using data sampling of 250 successful entrepreneurs from various industry sectors in Thailand. The data were analyzed by performing mean, standard deviation calculations, factor analysis and causal factors affected by LISREL program. Quantitative results showed that the model is consistent with empirical data.
\end{abstract}

\section{Keywords}

\section{Success Factors, Entrepreneurs, Thailand}

\section{Introduction}

Starting a business alone is already an enormous challenge that every entrepreneur must face. Every business is a venture. Entrepreneurs do not exactly know how business will evolve in the long run. There are only 2 outcomes, success or failure. There's no middle ground. However, entrepreneurs do not let these challenges stop them from realizing their goals for the business. Instead, these propel them to work even harder and bring out the best in every aspect of their business. Ha [1] (2013) stated that the major challenges faced by international entrepreneurs include internal factors such as cash management, cash flow, sales and marketing, fierce competition, founders' vision and external factors like political instability, economic pressure, interest rate environment, ever-changing consumer behavior and rapid technological change. Entrepreneurs seek various ways for success but the failure rate is high.

Siriwan et al. [2] (2013) conducted empirical entrepreneurs' research and found that entrepreneurs and owners of small and medium enterprises should notice the importance of business operation which focuses on business success. The success is based on four perspectives which are financial perspective, customer perspective, internal process perspective and learning and growth perspective. This finding supported BSC concept of Kaplan and Norton [3]-[8] (1993, 1996, 2000, 2001, 2004, 2006) who stated that BSC is an important tool for SMEs management to competitive advantages and critical success factors of SMEs in terms of operations both inter- 
nally and externally. The results of in-depth interviews with key opinion leaders found that small and medium enterprises in Northern Thailand should create strength in generating sustainable economic growth and competitive advantages by starting from developing innovation and new products to get competitive advantages in business and should be promoted by government organizations and other funding groups both local and national to help SMEs. Entrepreneurs' strategic management should focus on faster, better, and cheaper management model. SMEs should pay attention to time management, vision and mission of founders, organizational status of leaders, followers and strong work culture and work values, latest technology and latest management tools.

The small and medium entrepreneurs should consider major four factors affected the entrepreneurs' success consisted of (1) overall of the entrepreneurs' business, (2) the entrepreneurs' health and brain, (3) the entrepreneurs' investment, profit and stability and (4) the entrepreneurs' reputation, image and branding. These four aspects of success are strongly and unavoidable supported by the key three factors. Firstly, it called "time management”. Secondly, namely, organizational role consists of the role of leader, follower and consultant. Lastly, namely, work values include passion, effort, intention and carefulness. However, only a few of the above factors have been empirically studied, entrepreneurial management factors still remain unsolved. Therefore, additional investigation of the causal relationship among various success factors that affected successful entrepreneurs in Thailand was conducted. Research Hypothesis testing was as follows:

1) The variables which directly have the causal affected the success of entrepreneurs in Thailand are the demographic data of the entrepreneurs, including position and number of staffs, the characteristics and type of the business respectively.

2) The variables which directly have the causal affected the success of entrepreneurs in Thailand, are the factors which are time, role in the organization and work values respectively.

\section{Research Methodology}

We took three steps to conduct this research. In the beginning, we created the causal relationship framework among different factors affecting successful entrepreneurs using literature review and conducting face-to-face interviews. Then, we submitted the questionnaire to the experts for Content Validity. The experts examined the conformation and suitability of the questionnaire with the operational definition and suggested improvements. From the examination of Item Objective Congruence (IOC), it was found that the 25 questions have the value from 0.80 - 1.00. In the end, we used the approved questionnaires to try out with other non-actual-sample-sizes entrepreneurs to test reliability of the questionnaire by using Cronbach's Alpha Coefficient. The Reliability Coefficient score was 0.8157 . The correct and complete questionnaire was used to collect the data. The sampling size was 250 entrepreneurs in Thailand based on 2,652,854 SMEs entrepreneurs in Thailand. We analyzed data by using basic statistics, confirmatory factor analysis and linear structural equation model by the LISREL Program.

\section{Results}

In this research study, we analyzed data, basic statistics, confirmatory factor analysis and linear structural equations used. Results are shown in Figure 1.

\section{Discussions}

Based on Hypothesis testing 1, the variables which directly have the causal affected the success of the entrepreneurs in Thailand are the demographic data of the entrepreneurs, including position and numbers of staffs, the characteristic and type of the business respectively. Research result in Table1 indicated that the p value of the overall success of SMEs was greater than 0.005. It means that the different positions do not affect the different success of SMEs. When examining by each aspect, it was found that the p values of the success of SMEs in all aspects were greater than 0.005 , which means that the different positions do not affect the different success of SMEs. Therefore, the position does not affect the success of SMEs.

For the number of staff variable, it was found that the p value of the overall success of SMEs was less than 0.005. Research result indicated that the different numbers of staffs in an organization affect the different success of SMEs. When examining by aspect, it was found that the p value of the overall success of SMEs in the aspect of overall business and stability and reputation was less than 0.005 , which means that the different numbers of staff in an organization affect the different success of SMEs in the aspect of overall business and stability 


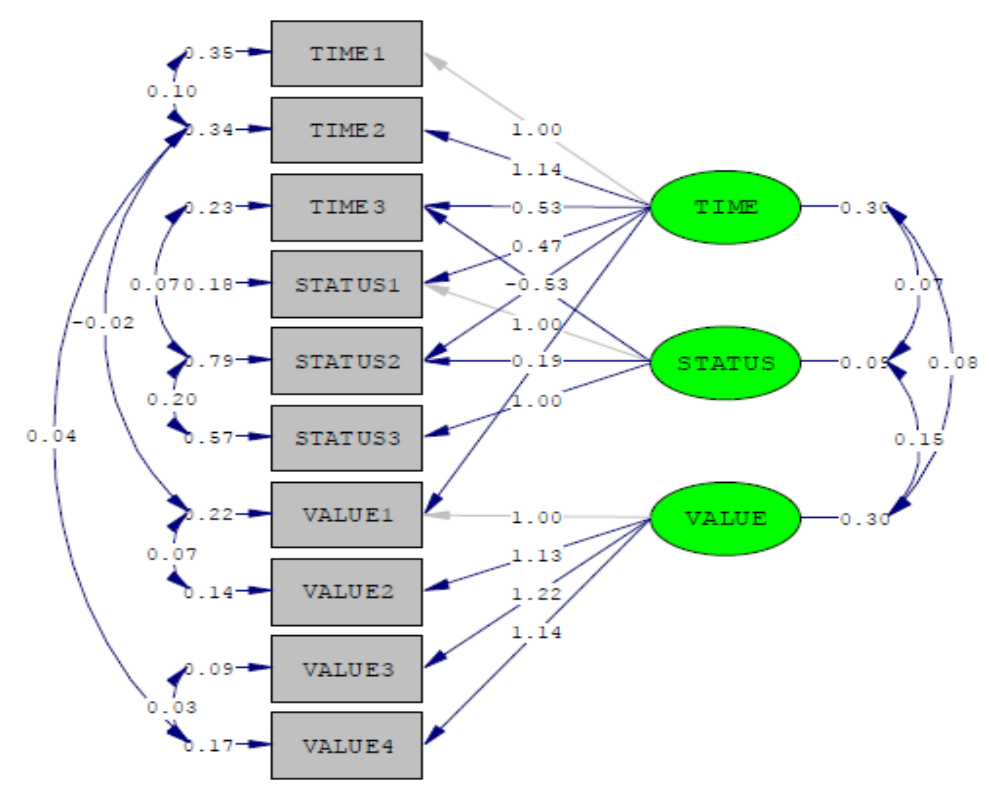

Figure 1. The model of the influence of the SMEs success variable $(\mathrm{n}=250)$. Chi-square $=40.96, \mathrm{df}=21, \mathrm{P}$-value $=0.00567, \mathrm{RMSEA}=0.046, \mathrm{GFI}=0.98$, AGFI $=0.95$, SRMR $=0.022$.

and reputation. The p value of the success of SMEs in the aspect of good health, mental health and brain, as well as the investment and profit, was higher than 0.005. It means that the different numbers of staff do not affect the success of SMEs in the aspect of the different good health, mental health and brain, investment and profit. Therefore, the numbers of staffs affect the success, we tested the difference in pair by using Least Significant Difference. It was found entrepreneurial organizations with 51 - 200 staffs have a higher level of success in the overall of the business than the SMEs entrepreneurs with less than 50 staffs in the organization. The SMEs entrepreneurs with more than 200 staffs in the organization have a higher level of success in the stability and reputation than those with less than 50 staffs in the organization. The reason why entrepreneurial organizations with 51 - 200 staffs have a higher level of overall success than those with less than 50 staffs in the organization is that larger enterprises get more comparative and competitive advantages which are the results of long-term business experience, a flexible management style and visionary leadership. Larger organizations have the leadership teamwork and east-meet-west good management when dealing with people of different backgrounds during different stages in a business cycle. Management and leadership also vary in the different periods. At the startup stage of the business, entrepreneurs grow a family business by do-it-yourself style to achieve business goals. Staffs are treated like family members and the work environment is harmonious and operational. Internal communication is efficient. The results are sales growth with proper cash management. However, when the business grows larger, management and leadership styles change dramatically. Reliable subordinates are assigned more responsibilities and freedom while the entrepreneurs focus on product development, business expansion or asset investment. They have more plans, make more decisions, employ external professionals or executives to join their organizations which are no longer family-run businesses. There are changes in management and leadership styles, shift in focus which deviates from the initial one and a lack of efficient communication which have an impact on business success.

For the characteristics of business, research result indicated the significant difference between private business and family-run business and family-run business with partnership. To discuss this point, we found that family-run businesses gain more advantages than private business while partnership businesses also gain more advantages than family-run businesses. The reasons are due to different time management style, organizational roles and work value. A family-run business manages time effectively when compared with a private business since the former has more people, more staff are involved in business activities. A private business works alone without an efficient team and proper time management. It also lacks of work-value since it spends most of its time making the business survive. Private businesses need to spend almost 24 hours daily since they perform as 
machines while family-run businesses can work on shifts. Partner businesses gain more comparative and competitive advantages due to work-related value such as vision, mission, goal and strategy. A partnership business works as a supply chain starting from sourcing of raw materials, production, transportation, end- product delivery and customer-servicing. It uses less time when compared with a private and family business. It performs professionally and we have found a significant difference in this variable.

For the different types of business, research result indicated that mostly these factors do not affect the different success of SMEs in the aspects of good health, mental health and brain, investment and profit and the stability and reputation. Only the types of business affect the overall success of SMEs, then we tested the difference in pair by using Least Significant Difference. It was found that SMEs entrepreneurs in the service sector enjoy a higher level of overall success than their counterparts in the brand manufacturing and design manufacturing sectors. So do SMEs entrepreneurs in the trading sector. Brand manufacturers have a higher level of overall success than OEM manufacturers. Major critical successful entrepreneurs came from the service sector, the trading sector and the brand manufacturing sector. In this factor, Thailand is famous for her international image as the land of services and smile. Her work-related value and background arose from the Thai culture. Regarding the trading sector, it is also found that Thailand is full of various products ranging from agricultural to industrial. The trading sector earns competitive advantages due to low cost of raw materials, low cost of skilled labors when compared with other competing countries and favorable government economic policies that encourage international businesses. For the brand manufacturing sector, entrepreneurs have family-DNA-incubated creativity and apply their experience to new and better business management, problem- solving, product innovation and new sales channels for a higher level of success. Moreover, they invent new machineries and tools, use the latest technology and raw materials for operation improvement, apply modern management effectively for cost reduction. The brand manufacturing entrepreneurs' creativity may come naturally or from adaptation to the concepts of innovators or researchers.

For the hypothesis 2, the variables which directly have the causal affected the success of entrepreneurs in Thailand, are the factors which are time, role in the organization and work values respectively.

Research result indicated that the independent variables consist of time (3 variables), role in the organizations (4 variables) and work values (4 variables). All independent variables have the causal affected the success of entrepreneurs in Thailand.

For the consistency check of the proposed model, the causal relationship of successful entrepreneurship in Thailand with empirical data, it was found that composition of latent variable consists of time for oneself, time for family and time for work all affects the success of entrepreneurs. Additionally, the role as the organization's leader, followers and consultant all affects the success of entrepreneurs. Finally, work values consists of passion, effort, intention and carefulness all affect the success of entrepreneurs in Thailand.

The empirical data used in the consistency check of the model are provided in Figure 1.

Overall, it was found that SMEs entrepreneurs scored the highest level to the time for work, the position of the organization's leader, passion, effort, intention and carefulness. They give the high precedence to the time for oneself, family and the role of the organization's consultants, and they give the average precedence to the position of the organization's follower. All variables have the highest value at 5 and lowest value at 1 . The Median of most variables was 4.00 except for the variable of the organization's leader that had a 5.00 Median. The time variables for work, the position of the organization's leader, passion, effort, intention and carefulness had the Mode of 5. The time variables for oneself, family, the organization's follower, had the Mode of 4 . We also analyzed the result of the relation between the observable variables. The analysis indicated the relationship between the observable variables in the study to verify the relationship between the independent variables for any problems about the multicollinearity and analyzed the statistics by Bartlett's test of sphericity, which is the hypothesis test to check whether the Covariance matrix is an identity matrix used as the basic information for the further examination of the model. It was found that among the 45 covariances most of them were medium positive with the value from -0.125 to 0.818 . With covariances not exceeding 0.80 , there is no multicollinearity. The statistical analysis of Bartlett's test of sphericity which is the statistics of hypothesis test whether the Covariance matrix is an Identity matrix, had the value of 2292.215 ( $p<0.01)$. It indicated the Covariance matrix of the observable variables of all samples was significantly different from an Identity matrix. It correlated with the index analysis by Kaiser-Mayer-Olkin which had the value of 0.837 which was closed to 1 . It meant that the observable variables of this data set had the internal relationship which was suitable for the further analysis of LISREL model. The analysis resulted in the consistency of the causal success of SMEs model with the empirical data. 
This part showed the data analysis of the accuracy of the causal relationship model between the aspect of time, role in the organization and work values, to examine whether the model conforms to the empirical data. The hypothesis of the examination is the covariance matrix-the covariance of the model of the hypothesis is equal to the covariance matrix-the covariance received from the empirical data. The details of the analysis result are listed below:

The model of causal relationship between the aspect of role in the organization and the work values in this study framework comprises the independent variables which are 3 latent variables including the latent variable of time (TIME), role in the organization (STATUS) and work values (VALUE). The latent variable of time (TIME) includes the observable variables of time for oneself (TIME1), time for family (TIME2) and time for work (TIME3). The latent variables of the role in the organization (STATUS) comprise the observable variables of the role as the organization's leader (STATUS1), the organization's follower (STATUS2) and the organization's consultant (STATUS3). The latent variables of the work values (VALUE) comprise the observable variables of the passion (VALUE1), effort (VALUE2), intention (VALUE3) and carefulness (VALUE4). We have total 10 observable variables in the analysis. The consistency test of the causal model of the SMEs success with the empirical data can be analyzed by specifying the unrelated error of the measurement for the variables. We found that the model of hypothesis was inconsistent with the empirical data, examining from the Chi-square, Degree of freedom and P-value. From the mentioned analysis, we modify the model of causal success for SMEs by allowing for the existence of an error in variables. For the model adjustment, we examine the Modification Indices and from this result, we obtained the model of causal success in the SMEs which was consistent with the empirical data as shown in Figure 1.

The research result indicated that the model was consistent with the empirical data, considering from the statistics used to examine the consistency of the model and the empirical data which include Chi-square of 40.96, Degree of freedom (df) is 21 at the probability (p) of 0.005 , which meant that the result from the test of Chisquare was not statistically different at 0.005 . The Root Mean Square Error Approximation (RMSEA) was 0.046 being less than 0.05 . It was also consistent with the result that the Goodness of Fit Index (GFI) was 0.98, the Adjusted Goodness of Fit Index (AGFI) was 0.95, closed to 1. The Standardized Root Mean Square Residual (SRMR) was 0.022 , closed to 0 . Therefore, the hypothesis was accepted that the model was consistent with the empirical data.

\section{Recommendations}

We now conclude our work with four recommendations.

1. It is highly important to transfer the knowledge from this empirical research to SMEs entrepreneurs in China and other countries to understand what factors affect business success;

2. It is recommended to apply the result of this study for the comparative establishment of stability and strength of the overseas Chinese and Chinese Thai SMEs entrepreneurs;

3. We suggest that the key success factors be employed as the business model for ASEAN and international SME business operation and management;

4. It is imperative for both public and private organizations to further study SMEs and large enterprises both qualitatively and quantitatively.

\section{Acknowledgements}

The authors would like to thank Xian Jiaotong — Liverpool University for supporting and sponsoring the presentation of this paper.

\section{References}

[1] Ha, M. (2013) Lecture Notes for Course: Entrepreneurial Finance, MSc. in Entrepreneurship \& Innovation for a Sustainable World. SKEMA Business School, Suzhou.

[2] Siriwan, U., et al. (2013) The Management of Small and Medium Enterprises to Achieve Competitive Advantages. Conference of the International Journal of Arts \& Sciences, 6, 154-156.

[3] Kaplan, R.S. and Norton, D.P. (1993) Putting the balanced scorecard to work. Harvard Business Review, 71, 134.

[4] Kaplan, R.S. and Norton, D.P. (1996) The Balanced Scorecard; Translating Strategy into Action. HBS Press, Boston.

[5] Kaplan, R.S. and Norton, D.P. (2000) Having Trouble with Your Strategy? Then Map It. Harvard Business Review, 78, 
167-176

[6] Kaplan, R.S. and Norton, D.P. (2001) The Strategy-Focused Organization: How Balanced Scorecard Companies Thrive in the New Business Environment. HBS Press, Boston.

[7] Kaplan, R.S. and Norton, D.P. (2004) Strategy Maps: Converting Intangible Assets into Tangible Outcomes. HBS Press, Boston.

[8] Kaplan, R.S. and Norton, D.P. (2006) Alignment: Using the Balanced Scorecard to Create Corporate, Synergies. HBS Press, Boston. 